\section{Electrodegradation of Root Exudates to Mitigate Autotoxicity in Hydroponically Grown Strawberry (Fragaria $\times$ ananassa Duch.) Plants}

\author{
Toshiki Asao², Hiroaki Kitazawa, Takuya Ban, and M. Habibur \\ Rahman Pramanik ${ }^{1}$ \\ Faculty of Life and Environmental Sciences, Shimane University, 2059 \\ Kamihonjo, Matsue, Shimane, 690-1102, Japan
}

\section{Kenzi Tokumasa}

Energia Economic and Technical Research Institute, Chugoku Electric Power Co. Inc., 3-9-1 Kagamiyama, Higashi-hiroshima, Hiroshima, 7390046, Japan

Additional index words. autotoxicity, benzoic acid, electrodegradation, hydroponics, strawberry plant

\begin{abstract}
Root exudates from strawberry plants are known to cause autotoxicity and benzoic acid (BA), a potent growth inhibitor, was found in the exudate. BA (400 $\mu \mathrm{M})$ was easily decomposed by electrodegradation (ED) treatment at $10.0 \mathrm{~V}$ and $2.0 \mathrm{~A}$ after the addition of BA into nutrient solution. The growth of strawberry plantlets in nutrient solution containing $B A(400 \mu M)$ or in control nutrient solution varied significantly depending on the use of ED treatment. The growth inhibition of plantlets in the BAcontaining nutrient solution or in nutrient solution used for strawberry culture was significantly ameliorated by ED treatment. This growth recovery resulting from ED treatment was most pronounced in terms of the yield of strawberry fruit. These results suggest that ED treatment of the culture nutrient solution could result in the decomposition of toxic root exudates, including BA from strawberry plants, and mitigates the autotoxicity observed in closed hydroponic culture. In addition, the supplementation of Fe-EDTA is recommended after ED treatment as a result of the rapid decomposition of Fe-EDTA by ED.
\end{abstract}

The soilless culture of a wide variety crops has been practiced in many countries since the $1950 \mathrm{~s}$, and the use of closed hydroponic systems has been encouraged recently (Ruijs, 1994; Van Os, 1995) to reduce environmental pollution and the cost of supplementary nutrients. A closed hydroponic system has been considered for strawberry cultivation (Takeuchi, 2000). However, the yield of strawberry fruit under continuous cropping conditions on the same substrate declined for unknown reasons (Oka, 2002). A lack of renewal of the nutrient solution in hydroponic culture significantly inhibited the growth of strawberry plants as a result of the accumulation of toxic root exudates in the nutrient solution, and benzoic acid was found to be the most potent inhibitor in the root exudates (Kitazawa et al., 2005). The removal/degradation of phytotoxic substances that have accumulated in the nutrient solution might reduce the growth inhibition

Received for publication 13 June 2008. Accepted for publication 28 July 2008 .

${ }^{1}$ Current address: Department of Crop Botany, Bangladesh Agriculture University, Mymensingh, 2202, Bangladesh.

${ }^{2}$ To whom requests for reprints should be addressed; e-mail asao@life.shimane-u.ac.jp of strawberry plants. Adsorption by activated charcoal (Asao et al., 1998; Kitazawa et al., 2005), degradation by microbial strains (Asao et al., 2004a), and auxin treatment (Kitazawa et al., 2007) have been tested for the detoxification of exudates. Degradation of toxic compounds by electronic means is another way to detoxify allelochemicals. Several phenolic compounds, including phenol (Comninellis and Pulgarin, 1991; Feng and Li, 2003; Fleszar and Ploszynka, 1985), catecol (Comninellis and Pulgarin, 1991), and hydroquinone (Comninellis and Pulgarin, 1991; Fleszar and Ploszynka, 1985), in aqueous solutions and even benzene were found to decompose when treated by electrodegradation (ED) (Fleszar and Ploszynka, 1985). These compounds are oxidized rapidly at the anode and decompose to $\mathrm{CO}_{2}$ (Comninellis and Pulgarin, 1991; Feng and Li, 2003; Fleszar and Ploszynka, 1985). Thus, ED might cause the decomposition of allelochemicals, including benzoic acid exuded into the nutrient solution from plants, and could be useful to mitigate autotoxicity in the hydroponic cultivation of strawberry. In this study, the effects of ED treatment of used nutrient solution or benzoic acid solution on the growth and yield of strawberry plants were investigated.
Decomposition of benzoic acid in the nutrient solution with or without electrodegradation treatment. Benzoic acid is a potent growth inhibitor in the root exudates of strawberry plants (Kitazawa et al., 2005). Four hundred micromolar benzoic acid solution was prepared using 30\% 'Enshi' nutrient solution (Table 1; Hori, 1966) with $0.8 \mathrm{dS} \cdot \mathrm{m}^{-1}$ electrical conductivity (EC). Fe-EDTA $\left(25 \mathrm{mg} \cdot \mathrm{L}^{-1}\right)$ was added to the nutrient solution. Tap water was used for the test solution preparation. One liter of this test solution was placed in a beaker and ED treatment was applied for $24 \mathrm{~h}$ with an electrode (cathode) consisting of a cylindrical titanium plate with a $180-\mathrm{cm}^{2}$ surface area and ferrite stick of $42 \mathrm{~cm}^{2}$ surface area (anode) inserted into the beaker (Fig. 1). The electric voltage and current in the ED process were $10.0 \mathrm{~V}$ and $2.0 \mathrm{~A}$, respectively. During the treatment, the test solution was stirred frequently and its temperature was maintained at $20^{\circ} \mathrm{C}$ using a water bath in an air-conditioned room at $18{ }^{\circ} \mathrm{C}$. Samples $(25$ $\mathrm{mL}$ ) of the treated solution were collected at 0 (control), 2, 6, 12, and $24 \mathrm{~h}$ during the ED treatment and filtered through a cellulose acetate membrane filter (pore size $0.45 \mu \mathrm{m}$ ). Each filtrate $(25 \mu \mathrm{L})$ was injected into a highperformance liquid chromatography (HPLC) system (column oven, detector, and pump: L2350, L-2400, and L-2130, respectively; Hitachi, Tokyo, Japan) to measure the concentration of benzoic acid in the nutrient solution. The analytical conditions were as follows: column: ODS $4.0 \times 200 \mathrm{~mm}$ (Wakosil 10C18; Wako Pure Chemical Industries, Ltd., Osaka, Japan); eluent: $\mathrm{CH}_{3} \mathrm{CN} / 10 \mathrm{~mm}$ $\mathrm{H}_{3} \mathrm{PO}_{4}=30 / 70(\mathrm{v} / \mathrm{v})$; flow rate: $1.0 \mathrm{~mL} \cdot \mathrm{min}^{-1}$ at $30{ }^{\circ} \mathrm{C}$; and detection: ultraviolet $254 \mathrm{~nm}$. EDTA was found to decompose by oxidation in the aqueous solution during ED treatment (Kusakabe et al., 1986). Thus, the concentration of Fe-EDTA (initial: $25 \mathrm{mg} \cdot \mathrm{L}^{-1}$ ) in the treated 'Enshi' nutrient solution was also measured by HPLC.

Effect of electrodegradation treated benzoic acid or used nutrient solution on the growth of strawberry plantlets (bioassay). Thirty percent 'Enshi' nutrient solution was prepared with tap water and the required amount of benzoic acid was added to reach $400 \mu \mathrm{M}$. Three liters of the test solution was poured into each plastic container $(17 \mathrm{~cm}$

Table 1. 'Enshi' nutrient solution ${ }^{\mathrm{z}}$.

\begin{tabular}{lc}
\hline Chemicals & $\begin{array}{c}\text { Amounts }^{\mathrm{y}} \\
(\mathrm{g} / 1000 \mathrm{~L})\end{array}$ \\
\hline $\mathrm{Ca}\left(\mathrm{NO}_{3}\right)_{2} \cdot 4 \mathrm{H}_{2} \mathrm{O}$ & 950 \\
$\mathrm{KNO}_{3}$ & 810 \\
$\mathrm{MgSO}_{4} \cdot 7 \mathrm{H}_{2} \mathrm{O}$ & 500 \\
$\mathrm{NH}_{4} \mathrm{H}_{2} \mathrm{PO}_{4}$ & 155 \\
$\mathrm{H}_{3} \mathrm{BO}_{3}$ & 3 \\
$\mathrm{ZnSO}_{4} \cdot 7 \mathrm{H}_{2} \mathrm{O}$ & 0.22 \\
$\mathrm{MnSO}_{4} \cdot 4 \mathrm{H}_{2} \mathrm{O}$ & 2 \\
$\mathrm{CuSO}_{4} \cdot 5 \mathrm{H}_{2} \mathrm{O}$ & 0.05 \\
$\mathrm{Na}_{2} \mathrm{MoO}_{4} \cdot 2 \mathrm{H}_{2} \mathrm{O}$ & 0.02 \\
\hline
\end{tabular}

${ }^{\mathrm{z} F u l l}$ strength.

${ }^{\mathrm{y}}$ Amounts of salts per $1000 \mathrm{~L}$ of tap water (Hori, 1966). 


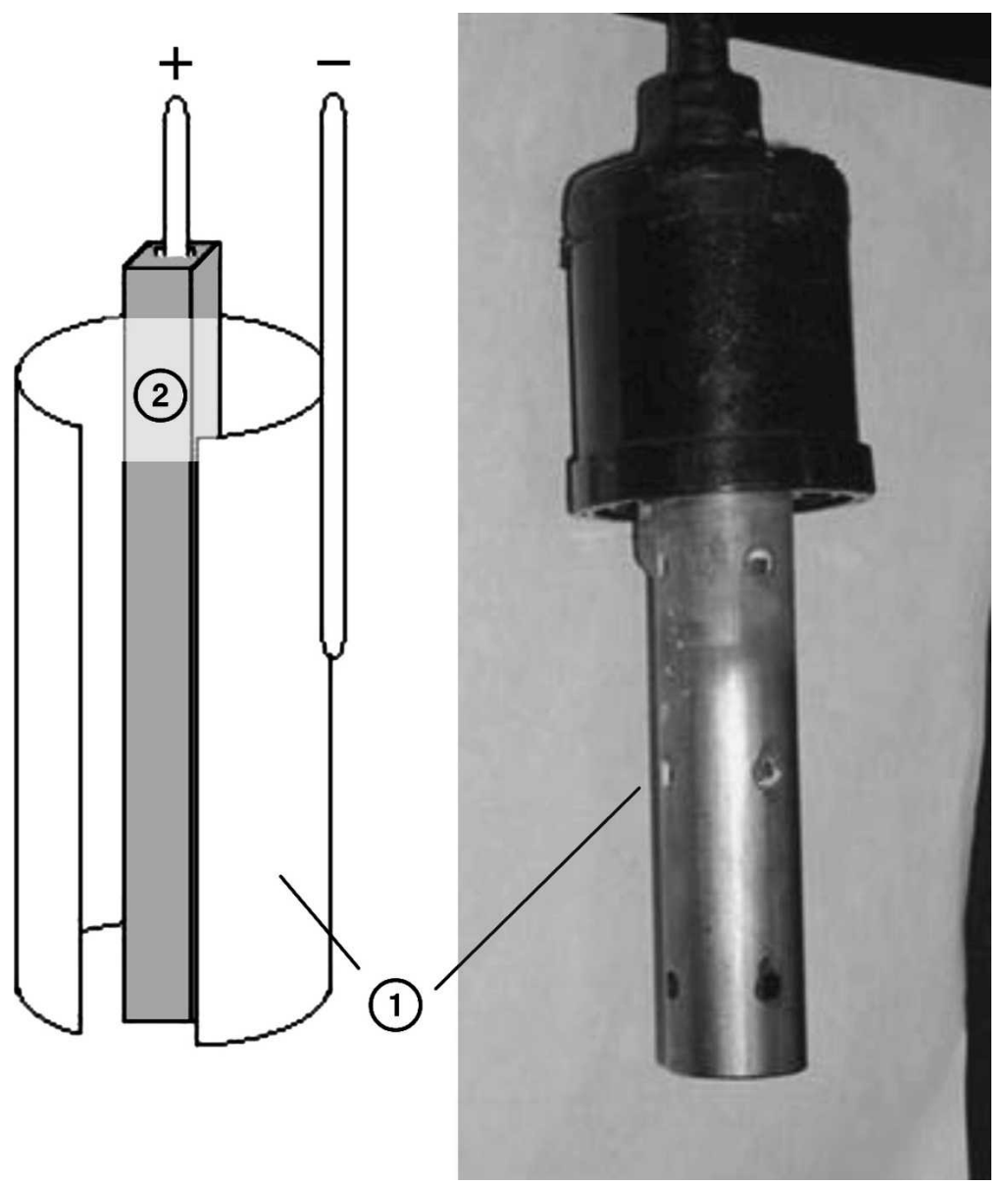

Fig. 1. Electrode used for the electrodegradation process to decompose benzoic acid or autotoxic chemicals in used/test nutrient solutions. (1) indicates the cathode made of titanium with a surface area of $180 \mathrm{~cm}^{2}$ and (2) indicates the anode (inside of cathode) made of ferrite with a surface area of $42 \mathrm{~cm}^{2}$.

$\times 29 \mathrm{~cm} \times 9.5 \mathrm{~cm}$ ) and then ED treatment was applied as described previously. Strawberry (Fragaria Xananassa Duch. var. 'Toyonoka') plantlets at the four-leaf stage were transplanted into the containers using urethane blocks (foam) as support.

The same bioassay was carried out with the nutrient solution used for strawberry culture as described previously (Kitazawa et al., 2005). The strawberry plants were grown using closed hydroponic culture without replacement of the nutrient solution. During the culture (Kitazawa et al., 2005), the nutrient contents $\left(\mathrm{NO}_{3}{ }^{-}, \mathrm{PO}_{4}{ }^{3-}, \mathrm{K}^{+}, \mathrm{Ca}^{2+}\right.$, $\mathrm{Mg}^{2+}$, and $\mathrm{Fe}^{3+}$ ) in the nutrient solution were adjusted at 2-week intervals to as close as possible to the initial concentrations on the basis of chemical analysis with a reflection meter (RQflex2; Merck, Tokyo, Japan) for $\mathrm{NO}_{3}^{-}$, the molybdenum blue molecular absorption spectrometric method (Murphy and Riley, 1962) for $\mathrm{PO}_{4}{ }^{3-}$, and atomic absorption spectrometer (Z-5010; Hitachi, Tokyo, Japan) measurements for $\mathrm{K}^{+}, \mathrm{Ca}^{2+}$, $\mathrm{Mg}^{2+}$, and $\mathrm{Fe}^{3+}$ analysis. After 8 months of strawberry culture, the used solution was adjusted again to match the initial nutrient concentrations and was frozen at $-30{ }^{\circ} \mathrm{C}$ to avoid microbial decomposition. This nutrient solution was used as the test solution for the bioassay and thawed out immediately before
ED treatment. The test solution was poured into a container and 10 plantlets were planted into each container with or without ED treatment. The solution in each container was replaced with additional solution from the same treatment at 4- or 5-d intervals. ED treatment was applied to the replacement solutions for $24 \mathrm{~h}$ as required. Fe-EDTA was added to the solution after ED treatment in each case. The $\mathrm{pH}$ and $\mathrm{EC}$ of each solution were measured using a $\mathrm{pH}$ meter (F-52; Horiba, Kyoto, Japan) and an EC meter (ES-12; Horiba), respectively. The $\mathrm{pH}$ and $\mathrm{EC}$ values were adjusted to be as close as possible to 30\% 'Enshi' nutrient solution ( $\mathrm{pH}$ 7.0 and EC $0.8 \mathrm{dS} \cdot \mathrm{m}^{-1}$ ) by adding $0.4 \mathrm{M}$ $\mathrm{NaOH}$ and/or tap water after the addition of sodium thiosulfate $\left(\mathrm{Na}_{2} \mathrm{~S}_{2} \mathrm{O}_{3} \cdot 5 \mathrm{H}_{2} \mathrm{O}\right)$. The $\mathrm{pH}$ of the solutions was unaffected by ED. The containers were placed in a growth chamber at $25{ }^{\circ} \mathrm{C}$ with a light intensity of 74 to 81 $\mu \mathrm{mol} \cdot \mathrm{m}^{-2} \cdot \mathrm{s}^{-1}$ and a $16-\mathrm{h}$ photoperiod under fluorescent lights. The plantlets were grown for 2 weeks and then the number of leaves, leaf length and width, leaf area, fresh weight of shoots, and the maximum root length were recorded. Leaf area (LA) was calculated by a nondestructive method (linear method) using the equation $\mathrm{LA}=\mathrm{L} \times \mathrm{B} \times \mathrm{K}$, where $\mathrm{L}$ is leaf length, $B$ is leaf breadth, and $K$ is a correction factor. $\mathrm{K}(0.53)$ was estimated by comparing the actual leaf area of 40 strawberry leaves measured in an electronic area meter to that measured by multiplying the length and breadth of the same leaves.

Effects of nonrenewal of the nutrient solution with or without electrodegradation treatment on the growth and yield of strawberry plants. A deep flow technique was used for the hydroponic cultures (Fig. $2)$. The hydroponic system was comprised of main pipes (15-mm diameter) for the supply and drainage of nutrient solution, Wagner pots with 3-L capacity for planting, tubes (4$\mathrm{mm}$ diameter) to supply solution to the pots, and a 50-L capacity nutrient solution tank with a pump (KP-101; Koshin, Kyoto, Japan) inside the nutrient solution. Strawberry var. 'Toyonoka' plantlets of uniform size (threeto four-leaf stage with $\approx 10 \mathrm{~mm}$ crown diameter) were transplanted into the pots on 16 Nov. 2005. The nutrient solution was circulated through the pipes for $5 \mathrm{~min}$ at 30 min intervals using an automatic pump timer (KS-1500; Iuchi, Osaka, Japan). The flow rate of the nutrient solution was $1 \mathrm{~L} \cdot \mathrm{min}^{-1}$. The nutrient solution was not renewed during the experiment. The nutrient $\left(\mathrm{NO}_{3}{ }^{-}, \mathrm{PO}_{4}{ }^{3-}\right.$, $\mathrm{K}^{+}, \mathrm{Ca}^{2+}, \mathrm{Mg}^{2+}$, and $\mathrm{Fe}^{3+}$ ) contents of the culture solution were adjusted at 2-week intervals to be as close as possible to the initial concentration of the 'Enshi' solution $(30 \%)$ based on the chemical analyses described previously. The same hydroponic system was followed by renewing the nutrient solution at 2-week intervals (control) or by furnishing ED treatment of the stock solution in the tank for $24 \mathrm{~h}$ at 2 -week intervals before the adjustment of the nutrient contents. The electric voltage and current for the ED were $18.0 \mathrm{~V}$ and $0.2 \mathrm{~A}$, respectively. In all cases, the EC and $\mathrm{pH}$ values of the nutrient solutions ranged from 0.7 to 1.2 $\mathrm{dS} \cdot \mathrm{m}^{-1}$ and 5.8 to 7.6 , respectively. One plantlet was planted in each pot and 10 pots were maintained for each treatment. The air and water temperatures during the experiment ranged from 13.1 to $28.1^{\circ} \mathrm{C}$ and from 15.6 to $25.4{ }^{\circ} \mathrm{C}$, respectively. Pollination was aided by vibrating the plants with a soft brush at 2-d intervals. During cultivation, the number of flower clusters and flowers, number of harvested fruits, and yield per plant were recorded. The fruits were harvested at maturity. At final harvest (1 June 2006), the number of leaves per plant, crown diameter, fresh and dry weight of shoots, dry weight of roots, and the maximum root length were recorded.

Data analysis. All data were analyzed to determine the statistical differences among the treatment means, and analysis of variance followed by mean separation with Tukey's test was conducted by using SPSS (SPSS Japan Inc., Tokyo, Japan) at a 5\% level of significance.

\section{Results and Discussion}

The degradation of benzoic acid (BA) in nutrient solution by electronic means (ED) was investigated. The amounts of BA (initially $400 \mu \mathrm{M}$ ) in the nutrient solution were 


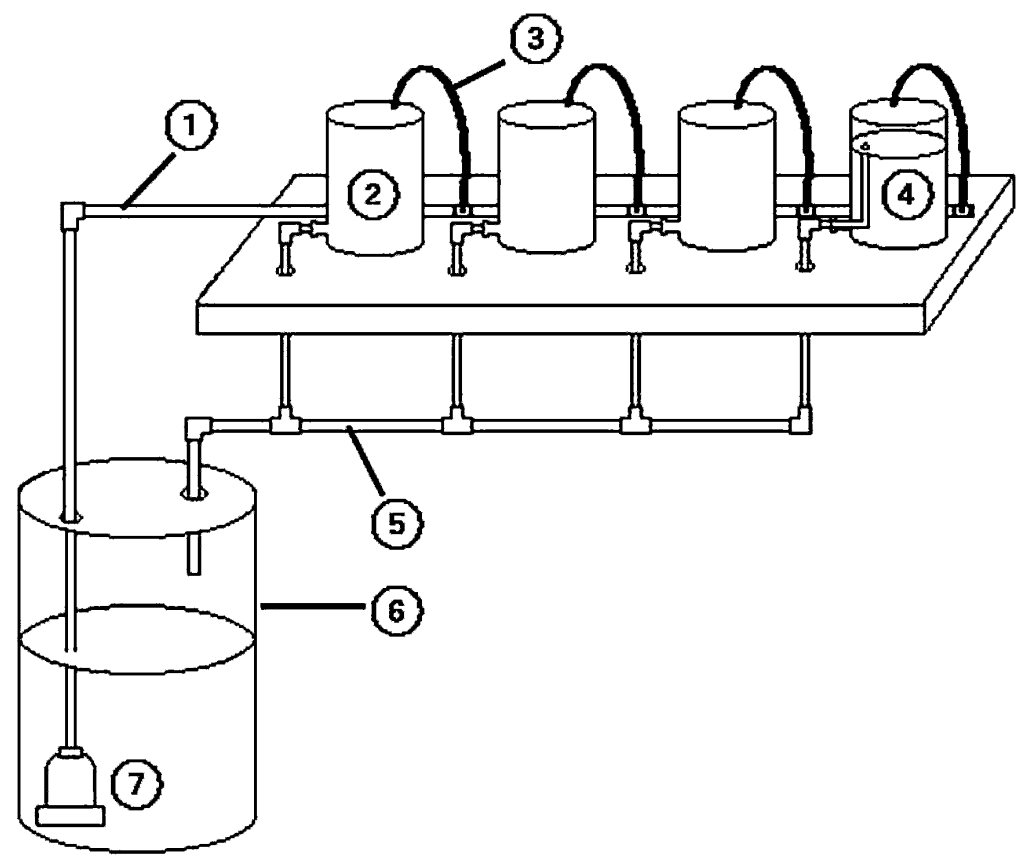

Fig. 2. The hydroponic system used for the cultivation of strawberry plants using a deep flow technique. The system comprised (1) main pipes (15-mm diameter) for supplying nutrient solution, (2) Wagner pots (3-L capacity) for planting, (3) tubes (4-mm diameter) to supply nutrient solution to the pots, (4) level of nutrient solution inside each pot, (5) pipes for the drainage of nutrient solution, (6) tank for stock nutrient solution (50-L capacity), and (7) pump in the solution tank for nutrient solution.

estimated by HPLC and were found to be $380,352,347$, and $324 \mu \mathrm{M}$ after 2, 6, 12, and $24 \mathrm{~h}$, respectively, without ED treatment (Fig. 3), whereas the BA concentration decreased to $259,223,185$, and $67 \mu \mathrm{M}$ after $2,6,12$, and $24 \mathrm{~h}$, respectively, after ED treatment. The BA concentration without ED treatment declined slowly even after $24 \mathrm{~h}$ compared with that with ED treatment. Similar results for several phenolic compounds in aqueous solutions have been reported previously (Comninellis and Pulgarin, 1991; Feng and Li, 2003; Fleszar and Ploszynka,

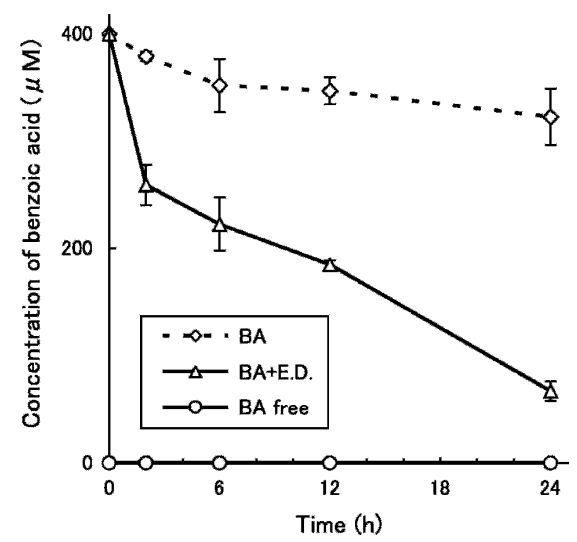

Fig. 3. Effect of electrodegradation on the concentration of exogenous benzoic acid (BA) in the nutrient solution. $\mathrm{BA}=$ initially $400 \mu \mathrm{M} \mathrm{BA}$ in the nutrient solution without electrodegradation (ED); $\mathrm{BA}+\mathrm{ED}=\mathrm{BA}$ in the nutrient solution with $\mathrm{ED}$; $\mathrm{BA}$ free = for nutrient solution without BA or ED. The vertical bars represent SE $(n=3)$. The electric voltage and current in the ED process were $10.0 \mathrm{~V}$ and 2.0 A, respectively.

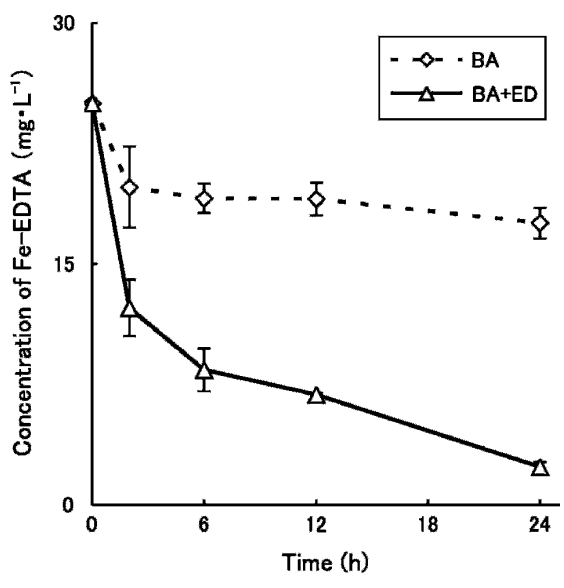

Fig. 4. Effect of electrodegradation on the concentration of Fe-EDTA (initially $25 \mathrm{mg} \cdot \mathrm{L}^{-1}$ ) in the nutrient solution. $\mathrm{BA}=$ the Fe-EDTA concentration in the nutrient solution with benzoic acid (BA) without electrodegradation (ED) and $\mathrm{BA}+\mathrm{ED}=$ the Fe-EDTA concentration in the nutrient solution after ED treatment. The vertical bars represent SE $(n=3)$. The electric voltage and current in the ED process were $10.0 \mathrm{~V}$ and $2.0 \mathrm{~A}$, respectively.

BA is one of the most potent growth inhibitors for plants. The ED treatment caused rapid BA decomposition (Fig. 3) resulting in a reduction of growth inhibition of strawberry plants compared with the control (Table 2). The used nutrient solution from strawberry culture not only contained BA, but also some other allelochemicals (Kitazawa et al., 2005). So, a bioassay was carried out with or without ED treatment of the nutrient solution with added BA $(400 \mu \mathrm{M})$ or with used nutrient solution after the cultivation of strawberry plants. The results revealed that the leaf number and root length did not differ significantly in any of the treatments (Table 2). However, the leaf length and width in the strawberry plants grown with BA decreased to $\approx 78 \%$ and $72 \%$, respectively, compared with the control. Plantlets grown with the used nutrient solution also decreased to $\approx 77 \%$ and $69 \%$, respectively, compared with the control. ED treatment of the BA solution or used nutrient solution mitigated these growth inhibition effects significantly to a point that they were statistically indistinguishable from the control. Consequently, the leaf area in the test strawberry plants was reduced significantly irrespective of the type of nutrient solution 
used without ED treatment and ED treatment significantly increased the growth of strawberry plants in used nutrient solution. The fresh weight of shoots of strawberry plants grown in BA solution or in used nutrient solution was significantly reduced to $\approx 55 \%$ and $61 \%$, respectively, compared with the control. ED treatment rescued the growth levels significantly by $170 \%$ and $158 \%$ compared with those grown in BA solution and in used solution, respectively, which were equivalent to the control. Significant growth inhibition of strawberry plantlets was reported after the addition of BA to the nutrient solution (Kitazawa et al., 2005, 2007). In this experiment, the shoot growth inhibition was induced by the BA solution as well as by the used nutrient solution. Because the decomposition of BA by ED treatment was confirmed (Fig. 3), it was suggested that the recovery of shoot growth was the result of ED treatment. The accumulation of growth inhibitors from the root exudates of tomato (Yu and Matsui, 1993), cucumber, taro, some leafy vegetables, and ornamentals (Asao et al., 1998, 2003, 2004b, 2007) in hydroponic nutrient solutions has been reported previously. The nutrient solution used in this study was the same as the solution used for strawberry culture by Kitazawa et al. (2005) in which significant growth inhibition (autotoxicity) was observed in strawberry plants. Thus, the conclusion was reached that the used nutrient solution contained growth inhibitors, including BA, and they caused the growth inhibition in strawberry plantlets. The alleviation of growth inhibition in strawberry plants grown in the used nutrient solution was concluded to be the result of ED treatment resulting in the decomposition of growth inhibitors, including BA.

To confirm the effect of ED on hydroponic culture, strawberry plants were grown in nutrient solutions with biweekly renewal (control), nonrenewed without ED, or nonrenewed with ED treatment. Table 3 shows that the number of leaves per strawberry plant in nonrenewed nutrient solutions with or without ED treatment decreased significantly to $\approx 59 \%$ and $60 \%$, respectively, compared with the control. In all treatments, the root length and crown diameter did not differ significantly. The fresh and dry weight of shoots decreased to approximately half, and the root dry weight declined significantly in the nonrenewed solution and the nonED-treated solution. However, the number of flowers in the nonrenewed solution decreased to $\approx 73 \%$ compared with the control. Consequently, the number of fruit harvested with the nonrenewed nutrient solution decreased to $56 \%$ compared with the control, whereas no statistical difference was observed between the control and ED-treated plants. The fruit yield in the nonrenewed nutrient solution declined by more than $50 \%$ compared with the control. ED treatment of the nutrient solution resulted in a significant recovery in fruit yield but not to the extent of the renewed nutrient solution (control). The growth inhibition of straw- berry in BA solution or in used nutrient solution was significant, and ED treatment mitigated this inhibition significantly (Tables 2 and 3). Growth inhibitors, including BA, in the root exudates of strawberry were considered to be decomposed by ED treatment. Thus, the ED treatment improved the growth of strawberry plants compared with untreated plants. However, the growth inhibition in the vegetative stage of strawberry plants grown in nonrenewed nutrient solution was not recovered significantly by ED treatment at 2-week intervals (Table 3).

This study shows that the effect of ED treatment was temporary and frequent ED treatment (less than 2-week interval) might be more effective to alleviate autotoxicity in strawberry. Finally, it could be concluded that ED treatment of the nutrient solution could mitigate the autotoxicity of strawberry plants grown by closed hydroponic culture. These results suggest that ED treatment at 2week intervals was not enough to support vegetative growth but was sufficient for fruit production. Further study is needed to determine the appropriate timing and intensity of ED treatment to maintain the nutrient solution and allow vigorous plant growth.

\section{Literature Cited}

Asao, T., K. Hasegawa, Y. Sueda, K. Tomita, K Taniguchi, T. Hosoki, and M.H.R. Pramanik. 2003. Autotoxicity of root exudates from taro. Scientia Hort. 97:389-396.

Asao, T., H. Kitazawa, K. Tomita, K. Suyama, H. Yamamoto, T. Hosoki, and M.H.R. Pramanik. 2004a. Mitigation of cucumber autotoxicity in hydroponic culture using microbial strain. Scientia Hort. 99:207-214.

Asao, T., H. Kitazawa, T. Ban, and M.H.R Pramanik. 2004b. Search of autotoxic substances in some leaf vegetables. J. Jpn. Soc. Hort. Sci. 73:247-249.

Asao, T., H. Kitazawa, K. Ushio, Y. Sueda, T. Ban, and M.H.R. Pramanik. 2007. Autotoxicity in some ornamentals with means to overcome it. HortScience 42:1346-1350.

Asao, T., M. Umeyama, K. Ohta, T. Hosoki, T. Ito, and H. Ueda. 1998. Decrease of yield of cucumber by non-renewal of the nutrient hydroponic solution and its reversal by supplementation of activated charcoal. J. Jpn. Soc. Hort. Sci. 67:99105 [in Japanese with English summary].

Comninellis, C.H. and C. Pulgarin. 1991. Anodic oxidation of phenol for waste water treatment. J. Appl. Electrochem. 21:703-708.

Date, S., S. Terabayashi, K. Matsui, T. Namiki, and Y. Fujime. 2002. Induction of root browning by chloramine in Lactuca sativa L. grown in hydroponics. J. Jpn. Soc. Hort. Sci. 71:485-489.

Feng, Y.J. and X.Y. Li. 2003. Electro-catalytic oxidation of phenol on several metal-oxide electrodes in aqueous solution. Water Res. 37:2399-2407.

Fleszar, B. and J. Ploszynka. 1985. An attempt to define benzene and phenol electrochemical oxidation mechanism. Electrochim. Acta 30:31-42.

Hori, Y. 1966. Gravel culture of vegetables and ornamentals. 3. Nutrient solution. Yokendo, Tokyo, Japan. p. 69-80 [in Japanese].

Kitazawa, H., T. Asao, T. Ban, Y. Hashimoto, and T. Hosoki. 2007. 2,4-D and NAA supplementation mitigates autotoxicity of strawberry in hydroponics. J. Appl. Hort. 9:26-30. 
Kitazawa, H., T. Asao, T. Ban, M.H.R. Pramanik, and T. Hosoki. 2005. Autotoxicity of root exudates from strawberry in hydroponic culture. J. Hort. Sci. Biot. 80:677-680.

Kusakabe, K., H. Nishida, S. Morooka, and Y. Kato. 1986. Simultaneous electrochemical removal of copper and chemical oxygen demand using a packed-bed electrode cell. J. Appl. Electrochem. 16:121-126.

Murphy, J. and J.P. Riley. 1962. A modified single solution method for the determination of phosphate in natural waters. Anal. Chim. Acta 27:31-36.

Oka, S. 2002. Development of the labor-saving cultivation techniques by raising the labor- saving cultivars of vegetables (Part 1). Bull. Natl. Agr. Res. Cent. Western Region. Okayama Prefecture. 13:26-27 [in Japanese].

Ruijs, M.N.A. 1994. Economic evaluation of closed production systems in glasshouse horticulture. Acta Hort. 340:87-94.

Sundin, P. and B. Watcher-Kristensen. 1994. Degradation of phenolic acids by bacteria from liquid hydroponic culture of tomato, p. 473475. In: Struik, P.C., W.J. Vredenverg, J.A. Renkama, and J.E. Parlevliet (eds.). Plant production on the threshold of a new century. Kluwer Academic Publishers, Dordrecht, The Netherlands.
Takeuchi, T. 2000. The nourishment uptake of strawberry cultivar 'Akihime' in rockwool hydroponics with a nutrient solution circulating system. Bull. Shizuoka Agr. Exp. Sta. 45:13-23. [in Japanese with English summary].

Van Os, E.A. 1995. Engineering and environmental aspects of soilless growing systems. Acta Hort. 396:25-32.

$\mathrm{Yu}$, J.Q. and Y. Matsui. 1993. Extraction and identification of the phytotoxic substances accumulated in the nutrient solution for the hydroponic culture of tomato. Soil Sci. Plant Nutr. 39:691-700. 